\title{
Research on Dynamic Response of Anchored Jointed Rock Slope under Traffic Load
}

\author{
Run LI*, Yasi WANG
}

\begin{abstract}
Based on the actual slope engineering, the dynamic response characteristics of the anchored joint slope in acceleration, velocity, and anchorage cable axial force under traffic load are numerically simulated. The results show that the cable axial force of the anchored slope starts to rise from the anchor head under traffic load, reaches a stable value in the free section, and falls to close to zero in the anchorage section. The axial force of the anchorage cable decreases when the slope height increases. Within the free section of the anchorage cable, there is a "small platform", where the axial force value decreases slightly and rises again, and its position corresponds to the range in which the anchorage cable passes through the joint. The dynamic response of traffic loads to the monitoring points of the slope is related to the magnitude of the load, the frequency, and the duration of the vibration. It is also related to the distance from the location of the traffic load, the physical and mechanical parameters of the location, the existence of joints, cracks and other structural planes, and whether or not to take support measures. When the frequency of the traffic load is close to the natural frequency of the slope, the resonance phenomenon is easy to occur, and the damage of the rock and soil of the slope is increased.
\end{abstract}

Keywords: dynamic response; jointed rock; rock anchoring; slope engineering; traffic load

\section{INTRODUCTION}

The construction of highways, railways and other infrastructure is currently booming in China, which extends to the mountains. For the rock slope along the road and railway, the internal stress field of the rock and soil changes continuously by the long-term influence of traffic load, and the strength of the rock and soil decreases with the accumulation of fatigue damage. The long-term safety and stability of the slope project are seriously affected, which inevitably brings massive slope problems related to traffic loads.

The dynamic response analysis of slopes has always been difficult in geotechnical engineering. The dynamic response of the slope includes acceleration, velocity, displacement response, and the like. The research on the dynamic response of slopes under dynamic loads has mainly focused on explosion and seismic load [1-3]. Traffic load is a cyclical load with a long period, low frequency, and large influence range. The deformation instability of rock and soil under this cyclic load has its particularity and complexity. The different frequencies, amplitudes, and duration of the traffic load will cause different responses of the rock slope. M. N. Bagde, V. Petroš [4] studied the fatigue behavior of sandstone integrality specimens under cyclic loading at different frequencies. The research shows that under certain effective energy, low frequency and low amplitude are more likely to destroy rock specimens than high frequency and high amplitude. Enlong Liu, Runqiu Huang, Siming He [5] studied the effects of loading frequency on the dynamic characteristics of rock mass integrality specimens by cyclic loading tests on sandstone integrality specimens under confining conditions. Fuenkajorn, K. \& Phueakphum, D. [6] conducted a uniaxial cyclic test on salt rock to study the effects of cyclic loading on uniaxial compressive strength, elastic modulus, and irreversible shape of salt rock. Abdelmagied, M. [7] analyzed the stability of the canal bank slope under traffic load by PLAXIS-2D finite element program. This paper studies the relationship of total displacement with traffic load, sand cohesion, and internal friction angle. The total displacement and stress of the embankment under dry and wet conditions were analyzed.

ABAQUS finite element software has a wide range of applications, which can solve most geotechnical problems. It has good applicability to geotechnical engineering and has been successfully applied in many fields such as geotechnical excavation, slope stability and seismic dynamic response analysis [8-10]. Based on the actual slope engineering, this paper simplifies the rock slope model by ABAQUS software, and numerically simulates the dynamic response characteristics of the anchored joint slope under acceleration, velocity, and anchorage cable axial force. In addition, some tentative discussions presents on its dynamic response law.

\section{THEORETICAL STUDY ON DYNAMIC RESPONSE OF ANCHORED JOINT SLOPE}

\subsection{Traffic Load Characteristics}

The effect of traffic load is that the ground vibration caused by the running of the vehicle and the unevenness of the road surface is transmitted to the roadbed through the road surface, and additional load is applied to the roadbed, and the vibration of the surrounding slope or building is caused by the propagation of the elastic wave. Traffic load belongs to the category of dynamic load, but it is different from short-term dynamic load such as earthquake and explosion. Traffic load as a cyclical load has a longer action period and lower frequency. The wavelength of the vibration wave generated by the load is longer and the wave propagates farther, the scope of influence and other characteristics. The vibration of traffic load is related to the level of road surface, vehicle type, driving velocity, and vehicle load. On the other hand, the vibration characteristics of the area around the road are also related to the highway infrastructure and surrounding rock layer structure.

\subsection{Vibration Cumulative Damage Effect of Traffic Load}

The cumulative damage effect is a dynamic manifestation of the material physical and mechanical properties. The current state of the cumulative damage effect is the dynamic superposition of its historical state, 
which is the result of the time history. Under the action of traffic load, the state of rock and soil materials dynamically superimposes, and the relevant mechanical parameters (stress, strain, and elastic constant) of the material are a function of time, related to historical mechanical processes.

The cumulative damage effect of traffic load on slope rock and soil is mainly manifested in two aspects. On the one hand, the weakening effect on the physical and mechanical properties of the geotechnical medium, and for the slope rock and soil mass affected by the traffic load for a long time, the original defects expand; new defects, the physical and mechanical properties of the slope rock and soil are weakening and even destroying. On the other hand, the resonance effect, the resonance effect of the rock and soil under the traffic load is mainly the filtering and frequency selection of the rock and soil. The performance, when the vibration frequency caused by traffic load is close to the natural frequency of the slope rock and soil, it is easy to produce resonance amplification.

\subsection{Selection of ABAQUS Calculation Model \\ 2.3.1 Mohr-Coulomb Elastoplastic Constitutive Model}

The Mohr-Coulomb elastoplastic constitutive model is widely used in geotechnical engineering. A large number of geotechnical engineering calculations use the MohrCoulomb model.

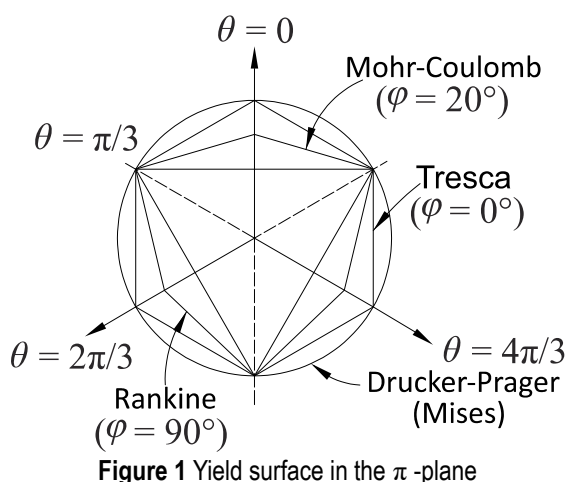

The Mohr-Coulomb yield criterion is the most commonly used criterion for describing geotechnical materials. For most geotechnical applications, the MohrCoulomb yield criterion is sufficiently accurate. The yield function form of the yield criterion is as follows.

$$
f\left(\sigma_{1}, \sigma_{2}, \sigma_{3}\right)=\frac{1}{2}\left(\sigma_{1}-\sigma_{3}\right)+\frac{1}{2}\left(\sigma_{1}+\sigma_{3}\right) \sin \varphi-\cos \varphi=0(1)
$$

In the formula, $\sigma_{1}, \sigma_{2}, \sigma_{3}$ represent the first, second, and third principal stresses. $c$ represents the cohesion of the material. $\varphi$ represents the internal friction angle of the material. In the $\pi$-plane, the Mohr-Coulomb yield surface is an equilateral and unequal hexagon, as shown in Fig. 1. Due to the sharp corners of the Mohr-Coulomb yield surface, if the associated flow rule is adopted, the plastic flow direction is not the only phenomenon at the sharp corners, which causes convergence difficulties. The MohrCoulomb constitutive model used by ABAQUS software is an extension of the classic Mohr-Coulomb yield criterion. The Mohr-Coulomb yield function used in the model includes isotropic hardening and softening of cohesive force. The shape of the flow potential function on the meridional plane is hyperbolic and continuously smooth on the $\pi$-plane, ensuring the Uniqueness.

\subsubsection{Numerical Simulation of Joints}

The joint material model provided in ABAQUS/Standard can be used to simulate jointed rock, but the model considers the rock as a material, which is full of joints. Take the case of the two joint groups shown in Fig. 2 as an example, you can see that the joint surface is distributed in the rock and interconnects each other. It is impossible to define the distribution density and spacing of the joint surface according to the actual situation, and only equivalent treatment can be done.

Literature [11] proposed a method of "brick-type" division of jointed rock, which can better simulate the rock controlled by joint surface. As shown in Fig. 3, the rock in a certain area is divided into "brick type". The "brick" is considered according to the rock materials, and the "brick joints" are considered according to the joint materials. Two sets of "brick joints" are two sets of joint surfaces (joint group 1, joint group 2), and two sets of "brick joints" intersection (joint group 3) have these two sets of joint faces pass, but the two upper and lower joints cannot be connected. The constitutive model of the "brick joint" area adopts the joint material model. The material parameters of two sets of joints are defined in the intersection area of "brick joints", and the Mohr-Coulomb model is used in the "brick" area.

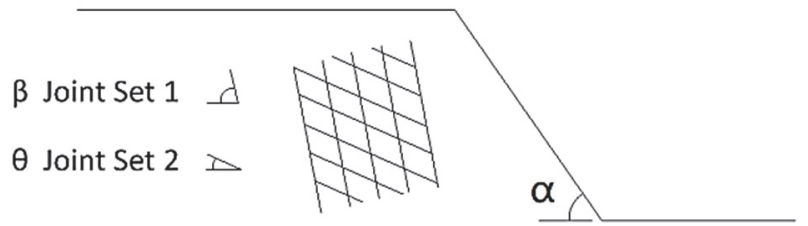

Figure 2 Cross section of rock slope with interpenetrated joint plane

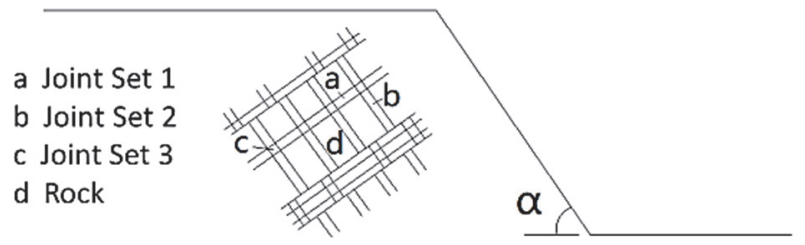

Figure 3 Cross section of rock slope with non-interpenetrated joint plane

\subsubsection{Numerical Simulation of Prestressed Anchorage Cable}

(1) Numerical simulation of anchorage cable

The anchorage cable is composed of an anchoring section, a free section, and an outer anchoring head. In order to facilitate the calculation and analysis of the problem, it is necessary to simplify the model properly, when building the model. In this simulation calculation, the free section (steel strand) adopts the linear elastic model, and the anchoring section and the anchorage cable frame are simplified into elastic materials.

(2) Application of anchorage cable prestress

The anchorage cable is prestressed by the temperature drop method. The temperature is set according to the Eq. (2). 
$T=-\frac{\sigma}{\alpha \cdot E}$

In the Eq. (2), $\sigma$ is the prestress value, $\alpha$ is the thermal expansion coefficient, and $E$ is the elastic modulus of the anchor cable.

\section{ESTABLISHMENT OF SLOPE DYNAMIC ANALYSIS MODEL}

\subsection{Project Overview}

Taking the high slope of a highway in Fujian Province as the background, the highway slope is divided into the upper slope and the lower slope. The upper slope is about $48.2 \mathrm{~m}$ high and the lower slope is about $22.2 \mathrm{~m}$, as shown in Fig. 4. According to the survey data, the rock joint fissures in the site are very developed, and three sets of joint fissures are developed in the exposed rock at the foot of the slope: $310^{\circ} \angle 70^{\circ}, 20^{\circ} \angle 60^{\circ}$ and $210^{\circ} \angle 60^{\circ}$. The distribution of rock and soil layers from top to bottom are: (1) silty clay, (2) residual sandy cohesive soil, (3) fully weathered tuff lava, (4) strongly weathered tuff lava, (5) weakly weathered tuff lava.

In this paper, the upper slope of highway is selected as the research object of numerical simulation. Anchor cable frames are adopted for the first, second and third stages of the upper slope. The excavation slope rate is 1:0.5 and the excavation height is $10 \mathrm{~m}$. The first stage of anchorage cable design tension is $500 \mathrm{kN}$, the free section is $10 \mathrm{~m}$, the anchoring section is $5 \mathrm{~m}$, and the inclination angle of the anchorage cable is $20^{\circ}$. The second and third anchorage cables are designed to have a tensile force of $500 \mathrm{kN}$, the free section is $15 \mathrm{~m}$, the anchoring section is $5 \mathrm{~m}$, and the cable inclination angle is $20^{\circ}$. The fourth stage adopts a herringbone skeleton to protect the grass, and the excavation slope rate is 1:1. Excavation intersects with the stratigraphic line.

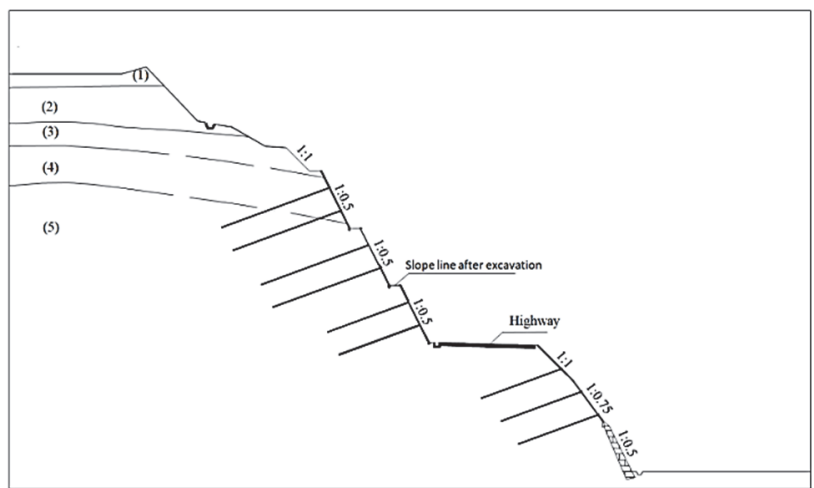

Figure 4 Slope engineering geological section

\subsection{Establishment of the Calculation Model 3.2.1 Simplification of the Calculation Model}

The actual site joint and fissures are very developed. In order to highlight the key points, the dynamic response characteristics of anchored joint slope under traffic loads are studied. In this paper, the joints with the inclination angle of $60^{\circ}$ with the greatest influence on the slope stability are selected. The six joints with the horizontal angle of $60^{\circ}$ are set in the first, second and third stages of the upper slope.

Boundary conditions have a great influence on the calculation results. The appropriate boundary condition is extremely important to choose the numerical simulation calculation. Mei, Y. et al, analyzed the effective impact of traffic load on the foundation, which is $18 \mathrm{~m} \mathrm{[12].} \mathrm{Chai,} \mathrm{J.}$ C. et al. calculated and analyzed the field measured data, and found that the effective impact depth of the vehicle load on the low fill embankment is about $6 \mathrm{~m}$ [13]. Li Xibin et al. considered the influence of pavement layer and fill embankment, and the roadbed depth of $15 \mathrm{~m}$ is taken to carry out finite element analysis of soft soil roadbed settlement under traffic load [14]. In this paper, the depth of the rock and soil mass under the traffic load position is at $20 \mathrm{~m}$, and the bottom surface of the model can be considered to have the depth of influence under the traffic load.

In the finite element analysis calculation process of this paper, the vehicle load is simplified to a periodic harmonic load, the range is $1.5 \mathrm{~m}$, and it is expressed as $F=\hat{F} \sin (2 \pi f t)$ in the form of sine wave. This paper simulates different vehicle load and driving velocity by taking different values of load $\hat{F}$ and frequency $f$.

\subsubsection{Establishment of the Unit Model}

Modeling by ABAQUS software, the slope adopts 3 nodes plane triangle element (CPE3), the anchorage cable adopts beam unit (B21), and the frame and anchor section adopt plane strain unit (CPE4R). The boundary conditions are set as follows. The horizontal and vertical displacement constraints are set at the bottom of the model, and the horizontal displacement constraints are set on the left and right sides, and the road surface and the slope surface are free surfaces. The model is established as shown in Fig. 5 and Fig. 6.

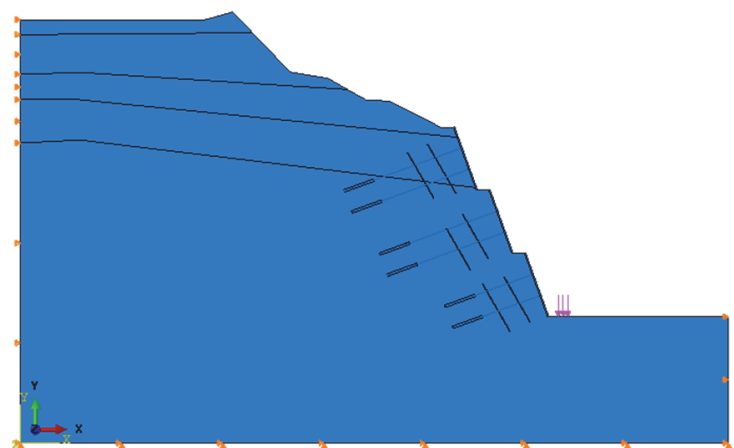

Figure 5 Overall model of the slope

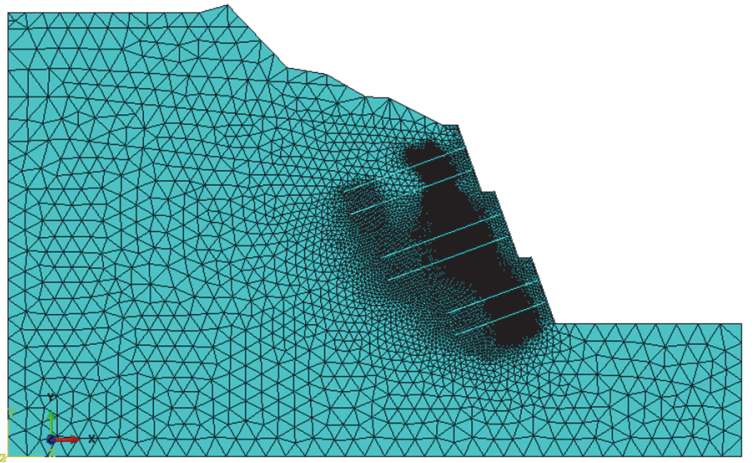

Figure 6 Overall grid of the slope 


\subsection{Selection of Calculation Parameters 3.3.1 Material Parameters}

The physical and mechanical parameters of the materials used in this paper are shown in Tab. 1. The parameters are taken from the survey data and engineering experience values of the area.

\begin{tabular}{|c|c|c|c|c|c|}
\hline Material & $\begin{array}{l}\text { Density } \\
\rho / \mathrm{kgm}^{-3}\end{array}$ & $\begin{array}{c}\text { Cohesion } \\
c / \mathrm{kPa}\end{array}$ & $\begin{array}{c}\text { Internal } \\
\text { friction } \\
\text { angle } \\
\varphi /^{\circ}\end{array}$ & $\begin{array}{l}\text { Poisson's } \\
\text { ratio } v\end{array}$ & $\begin{array}{c}\text { Elastic } \\
\text { modulus } \\
E / \mathrm{kPa}\end{array}$ \\
\hline Silty clay & 1700 & 15 & 15 & 0.3 & $2 \mathrm{E} 4 *$ \\
\hline $\begin{array}{c}\text { Residual } \\
\text { sandy } \\
\text { cohesive soil }\end{array}$ & 1720 & 13 & 19.9 & 0.3 & $2 \mathrm{E} 3 *$ \\
\hline $\begin{array}{c}\text { Fully } \\
\text { weathered tuff } \\
\text { lava }\end{array}$ & 2000 & 28 & 18 & 0.35 & $2.5 \mathrm{E} 5$ \\
\hline $\begin{array}{c}\text { Strongly } \\
\text { weathered tuff } \\
\text { lava } \\
\end{array}$ & 2320 & 35 & 25 & 0.31 & $6.5 \mathrm{E} 5$ \\
\hline $\begin{array}{c}\text { Weakly } \\
\text { weathered tuff } \\
\text { lava }\end{array}$ & 2580 & 100 & 40 & 0.27 & $6 \mathrm{E} 6$ \\
\hline $\begin{array}{l}\text { Structural } \\
\text { surface }\end{array}$ & 2500 & 20 & 30 & 0.3 & $3 \mathrm{E} 5$ \\
\hline Concrete & 2500 & - & - & 0.21 & $2.67 \mathrm{E} 7$ \\
\hline Anchor & 7850 & - & - & 0.3 & $1.95 \mathrm{E} 8$ \\
\hline
\end{tabular}

Note: * indicates that the parameter taken is the deformation modulus.

\subsubsection{Damping Parameters}

When an undamped system is given free vibration, its amplitude remains constant. However, in the dynamic problem, any structure has large or small damping. The size of the damping has a certain influence on the dynamic response of the system. In engineering, the linear combination of the mass matrix and the stiffness matrix is often used, namely Rayleigh damping.

Rayleigh damping assumes a linear combination of damping matrix mass and stiffness matrices.

$$
C=\alpha M+\beta K
$$

$\alpha$ is the mass damping coefficient and $\beta$ is the stiffness damping coefficient. In general, Rayleigh damping is not reliable for large damping systems (that is, damping systems that exceed the critical damping by about $10 \%$ ). For a given mode $i$, the critical damping ratio is $\xi_{i}$, and the relationship between the Rayleigh damping value $\alpha$ and $\beta$ are as follows.

$\xi_{i}=\frac{\alpha}{2 \omega_{i}}+\frac{\beta \omega_{i}}{2}$

$\omega_{i}$ is the $i$-th order natural angular frequency of the model, and $\xi_{i}$ is the corresponding damping ratio.

In this paper, Rayleigh damping is used. According to experience $\xi=0.003$, the mode shape and natural frequency of the model are obtained through the frequency extraction analysis step frequency in ABAQUS. The mass damping factor $\alpha=0.219$ and the stiffness-damping factor $\beta=0.003$ are determined by calculation.

\section{DYNAMIC RESPONSE ANALYSIS OF ANCHORED JOINT SLOPE UNDER TRAFFIC LOAD}

In the process of finite element analysis and calculation in this paper, the vehicle load is simplified to a periodic harmonic load, expressed as the form of a sine wave $F=\hat{F} \sin (2 \pi f t)$, and the simulation of different vehicle load and driving velocity is achieved by different values of load $\hat{F}$ and frequency $f$. Six monitoring points $(A \sim F)$ are selected on the slope and the anchor cables are numbered. The anchor cables (anchor-1 to anchor-6) are numbered from the foot of the slope, as shown in Fig. 7. On this basis, the dynamic response of the anchored joint slope under traffic load is analyzed.

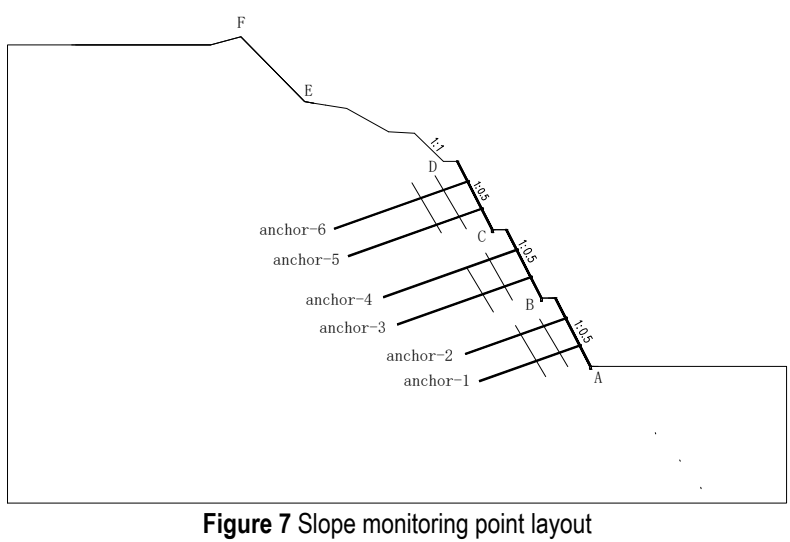

\subsection{Influence of traffic load on anchor cable axial force}

For a simplified traffic load sine wave $F=\hat{F} \sin (2 \pi f t)$, $\hat{F}=10 \mathrm{kPa}$ and $f=9 \mathrm{~Hz}$ are taken. This paper analyzes the axial force of each anchor cable before and after the traffic load. Fig. 8 is an axial force diagram of six rows of anchor ropes at three steps of the slope after 7 seconds of traffic load.

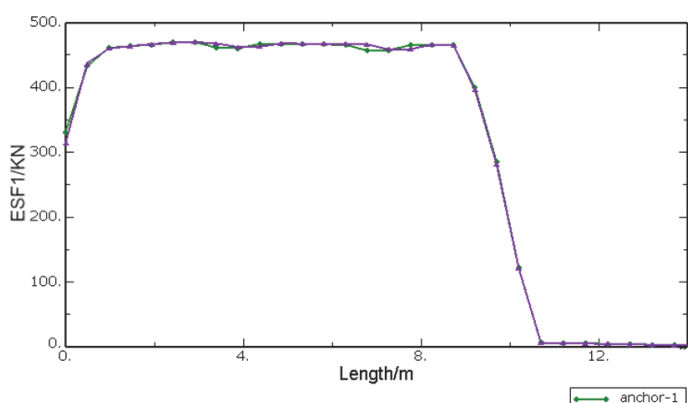

(a) Axial force diagram of the first step anchor cable

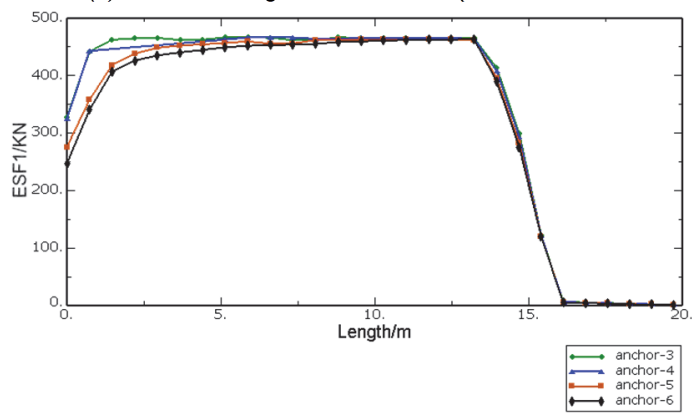

(b) Axial force diagram of second and third step anchor cable Figure $\mathbf{8}$ Axial force diagram of each anchor cable of the slope 
Fig. 8 shows:

(1) The axial force variation trend of each anchorage cable is generally the same, the axial force starts to rise from the anchor head, and rises to a relatively stable axial force value from the anchor head at $1 \mathrm{~m} \sim 2.2 \mathrm{~m}$ of the free section. From $1.3 \mathrm{~m}$ to $1.7 \mathrm{~m}$ of the anchorage section, the axial force continues to decrease after entering the anchorage section until the axial force is close to zero.

(2) The axial force of each anchorage cable gradually decreases with the growth of the slope height, that is, the axial force of the lower anchorage cable is greater than the axial force of the upper anchorage cable. This is because the weight of rock and soil of the lower-level anchorage cable is greater than that of the upper-level anchorage cable. Therefore, the anchorage cable is closer to the foot of the slope, the axial force of the anchorage cable is smaller.

(3) Within the free section of each anchorage cable, one or two "small platforms" with slight drops and rises appear in the axial force curve. Further analysis shows that the positions of these "small platforms" correspond to a short range of each anchor cable passing through the joint. In this paper, the numerical simulation shows that the cohesive force imparted to the joint material is much smaller than the cohesive force of the stratum where the joint is located, and the joint material can be regarded as a loose structural surface. Due to the existence of these loose structural planes, the axial force of the anchorage cable changes significantly when passing through the structural plane, and a small platform that drops and rises slightly on the axial force curve. In the literature [15], in the study of the distribution law of the rod body stress along the anchoring direction in the cavity resin anchor, it is also pointed out that the hollow resin anchor in the drawn state will have an obvious "pull stress platform" in the anchoring cavity position. In the actual project, the axial force curve of the measured anchorage cable is analyzed. If there is a "small platform" in the axial force curve, it can help to determine whether there is a loose or broken structural surface or cavity in the rock, and infer the range of its location.

In order to further study the influence of traffic load on the axial force of the anchorage cable, the axial force of each anchorage cable with or without the traffic load is analyzed, as shown in Tab. 2.

Table 2 Axial force of anchor cables before and after traffic load

\begin{tabular}{|c|c|c|c|}
\hline \multirow{2}{*}{ Anchor NO. } & \multicolumn{2}{|c|}{ Anchor cable axial force maximum / kN } & \multirow{2}{*}{ Anchor cable axial force change / kN } \\
\cline { 2 - 3 } & Before traffic load & After traffic load & \\
\hline anchor-1 & 469.678 & 469.731 & 0.053 \\
\hline anchor-2 & 469.667 & 469.706 & 0.039 \\
\hline anchor-3 & 465.898 & 465.923 & 0.025 \\
\hline anchor-4 & 465.797 & 465.820 & 0.023 \\
\hline anchor-5 & 463.057 & 463.050 & -0.007 \\
\hline anchor-6 & 462.132 & 462.126 & -0.006 \\
\hline
\end{tabular}

Tab. 2 shows that although the traffic load of the simulation for $7 \mathrm{~s}$ has little effect on the axial force of each anchorage cable, there are still certain rules.

(1) Under the traffic load, the maximum value of the axial force change of the anchorage cable is the lower row of the first anchor (anchor-1) at the first step closest to the traffic load.

(2) For the four rows of anchorage cables (anchor$1 \sim$ anchor-4) located at the first and second step, the axial force change value of the anchorage cable decreases as the distance from the traffic load increases.

(3) The two rows of anchorage cables (anchor-5, anchor-6) located at the third step are affected by the distance from the traffic load, and the impact is minimal.

The axial force of each anchorage cable within $0 \sim 7 \mathrm{~s}$ of traffic load time is compared and analyzed, as shown in Fig. 9.

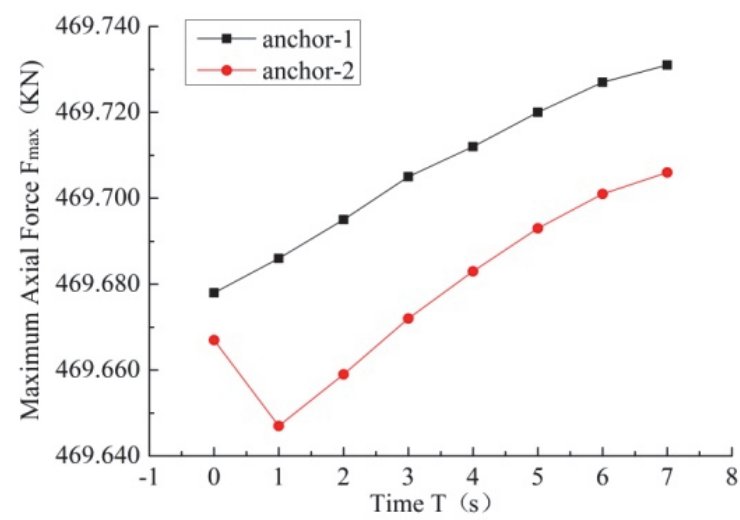

(a) First step

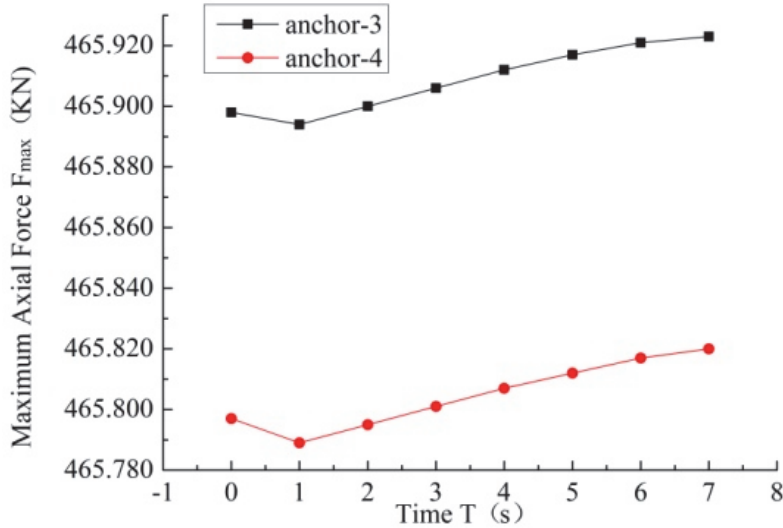

(b) Second step

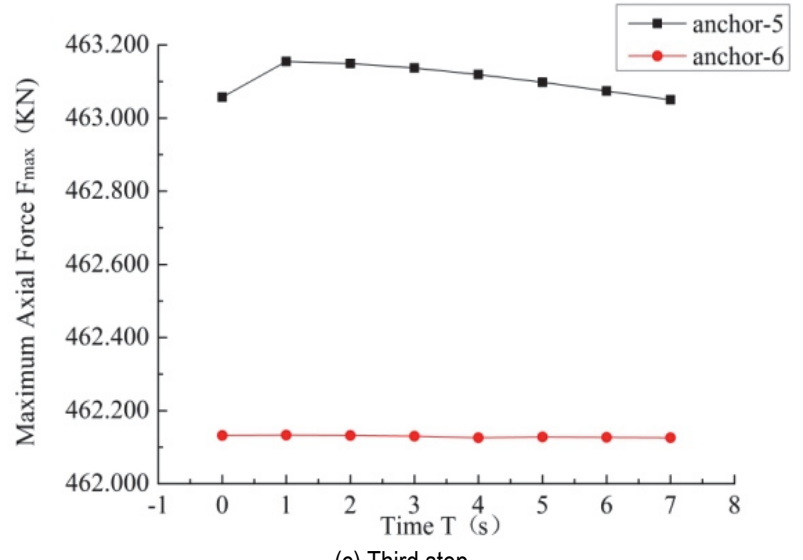

(c) Third step

Figure 9 Curve of axial force of each anchor cable on the slope with the traffic load time 
Fig. 9 shows:

(1) Under the action of traffic load, the axial force of anchorage cable anchor-1 continues to rise;

(2) The anchorage cable (anchor-2 anchor-4) has a decrease in axial force when the traffic load is $0 \sim 1 \mathrm{~s}$. With the continuous action of traffic load, the axial force is increasing.

(3) The anchorage cable (anchor-5 and anchor-6) has a growth in axial force when the traffic load is $0 \sim 1 \mathrm{~s}$. With the continuous action of traffic load, the axial force begins to decline again.

Analyze the possible causes: the anchor (anchor-1) and its adjacent slope are closest to the traffic load. During $0 \mathrm{~s}$ to $7 \mathrm{~s}$ of continuous traffic load, the displacement of the slope increases continuously, so the axial force of the anchor-1 always shows an upward trend. When the traffic load is $0 \sim 1 \mathrm{~s}$, the axial force of anchorage cable for anchor- $2 \sim$ anchor- 4 is reduced by the traffic load. As the traffic load continues to act, the slope begins to shift and the anchorage cable axial force increases. Because the location layer parameters are low, when the traffic load is $0 \sim 1 \mathrm{~s}$, the slope of the anchorage cable (anchor-5, anchor6 ) is displaced, and the axial force appears to rise. However, because the section is the farthest from the traffic load, the axial force is less affected by the traffic load. As the traffic load continues to act, the lower anchorage cable begins to function. The axial force of the anchor (anchor-5 and anchor-6) began to fall back.

\subsection{Influence of Different Traffic Loads}

For the simplified traffic load sine wave $F=\hat{F} \sin (2 \pi f t)$, as $f=9 \mathrm{~Hz}$ and the action time is $7 \mathrm{~s}$. In this paper, $2.5 \mathrm{kPa}, 5 \mathrm{kPa}, 7.5 \mathrm{kPa}, 10 \mathrm{kPa}$ and $12.5 \mathrm{kPa}$ are taken by $\hat{F}$ respectively, and the influence of different traffic loads on the anchored joint slope is analyzed.

\subsubsection{Analysis of Acceleration and Velocity of Joint Slope}

Fig. 10 shows the acceleration and velocity changes of the monitoring points on the jointed slope after $7 \mathrm{~s}$ of traffic load with the same frequency and different load.

Fig. 10 shows:

(1) The acceleration of each monitoring point increases with the growth of the load. The monitoring point $\mathrm{A}$ is closest to the traffic load and the acceleration of point A increases the most. The acceleration increase is the smallest for the monitoring point $F$ that is farthest from the traffic load. That is, under the same load, the point acceleration of vibration response closest to the traffic load is the most sensitive and the growth is the largest. The acceleration vibration response at the point farthest from the traffic load is the least sensitive and the growth is minimal.

(2) The velocity of each monitoring point also increases as the load increases. The growth rate of the monitoring point $D$ is the largest, and the growth rate of the monitoring point $F$ is the smallest, which is related to the formation parameters and the calculated velocity of the monitoring point.

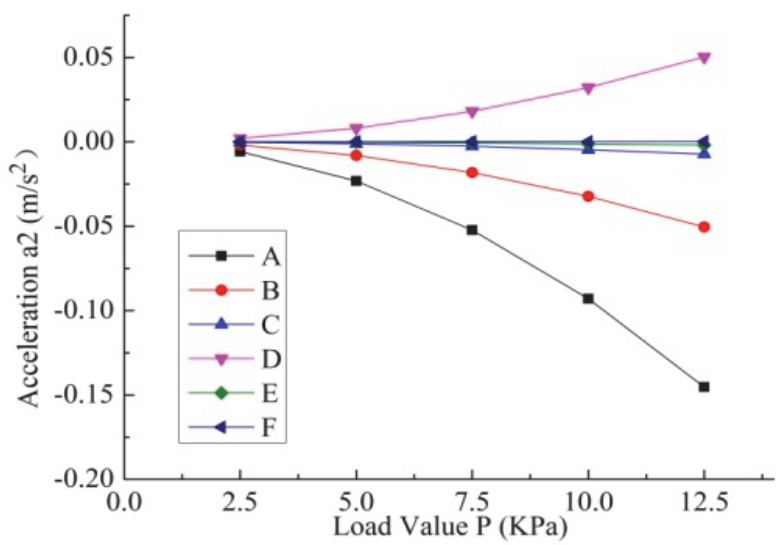

(a) Acceleration $a_{2}$

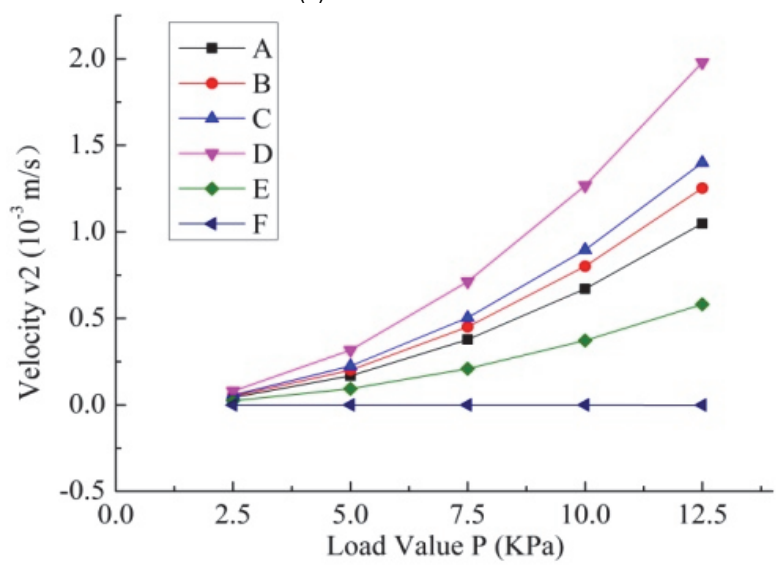

(b) Velocity $v_{2}$

Figure 10 Acceleration and velocity of each monitoring point under traffic load of the same frequency and different load

\subsubsection{Anchorage Cable Axial Force Analysis}

Fig. 11 shows the maximum axial force variation of each anchorage cable after $7 \mathrm{~s}$ of traffic load with the same frequency and different load.

Fig. 11 shows:

(1) The axial force of each anchorage cable decreases with the growth of the slope height, that is, decreases with the growth of the load distance;

(2) The axial force of the four rows of anchorage cables (anchor-1 anchor-4) of the first and second steps increases with the growth of the load, and the axial force of the anchor-1 closest to the traffic load increases the most;

(3) The axial force of the two rows of anchorage cables (anchor-5, anchor-6) at the third step first decreased, and then increased.

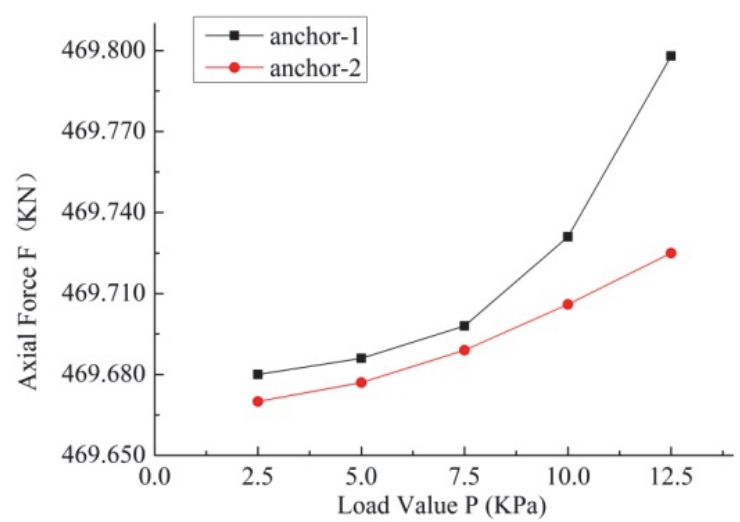

(a) anchor-1, anchor-2 


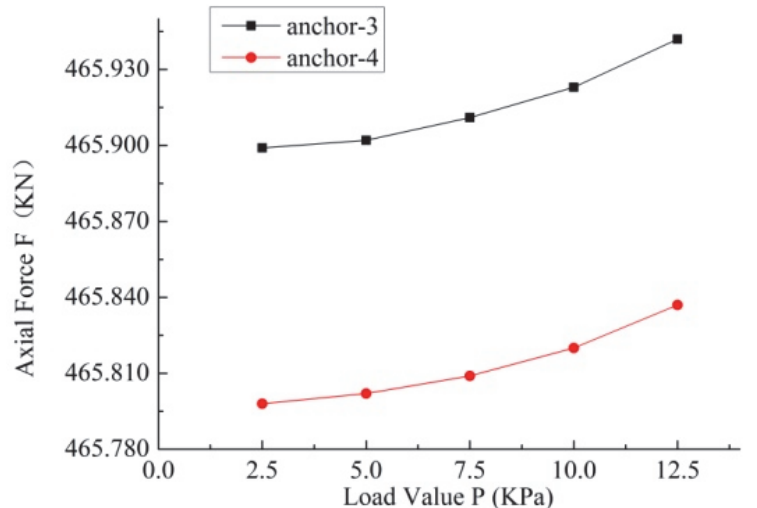

(b) anchor-3, anchor-4

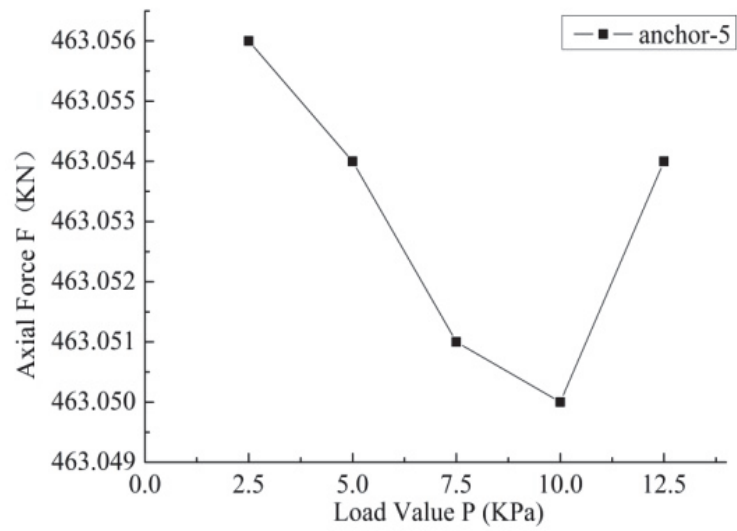

(c) anchor-5

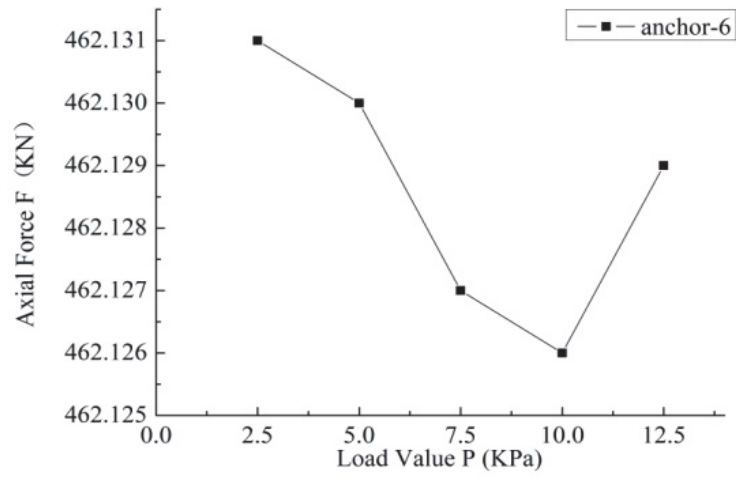

(d) anchor-6

Figure 11 Maximum axial force of each anchor cable under the same frequency and different load

\subsection{The Impact of Different Driving Velocity}

For the simplified traffic load sine wave $F=\hat{F} \sin (2 \pi f t), \hat{F}=10 \mathrm{kPa}$ is set, the action time is $7 \mathrm{~s}$, $f$ takes $1 \mathrm{~Hz}, 3 \mathrm{~Hz}, 5 \mathrm{~Hz}, 7 \mathrm{~Hz}, 9 \mathrm{~Hz}$, respectively, and the influence of different driving velocity on the anchored joint slope is analyzed.

\subsubsection{Analysis of Acceleration and Velocity of Joint Slope}

Fig. 12 shows the changes in acceleration and velocity at each monitoring point on the joint slope. The changes occurred after $7 \mathrm{~s}$ of the same traffic load and different frequencies.

Fig. 12 shows:

(1) The acceleration of the monitoring points A and $\mathrm{B}$ increases as the frequency increases. The acceleration of the monitoring points $\mathrm{C}$ and $\mathrm{D}$ shows a significant inflection point at the frequency of $7 \mathrm{~Hz}$. The acceleration of the monitoring points $\mathrm{E}$ and $\mathrm{F}$ shows a significant growth at the frequency of $5 \mathrm{~Hz}$.

(2) The velocity of monitoring points A, B, C, and D shows a significant inflection point at the frequency of 7 $\mathrm{Hz}$. The velocity of the monitoring points $\mathrm{E}$ and $\mathrm{F}$ shows a significant increase at the frequency of $5 \mathrm{~Hz}$.

It can be considered that the frequency band of $5-7 \mathrm{~Hz}$ is similar to the natural frequency of the simulated slope in this paper. Traffic load and slope are prone to resonance, and the growth in amplitude of each monitoring point is related to the location of the slope and the parameters of the formation.

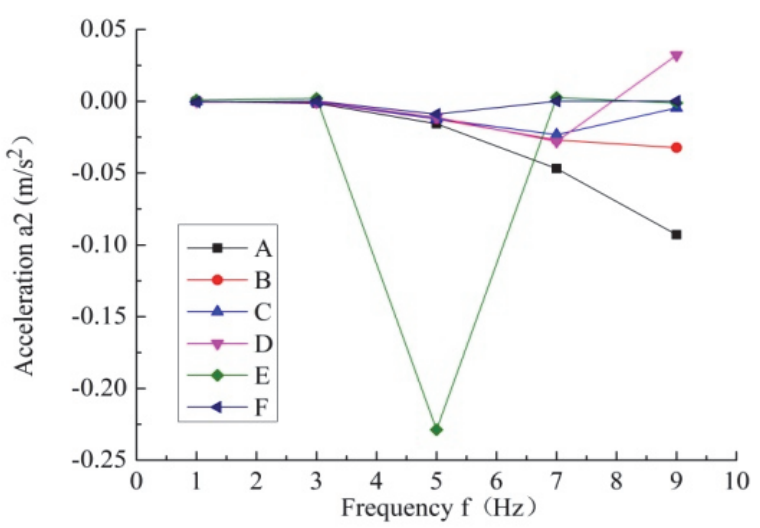

(a) Acceleration $a_{2}$

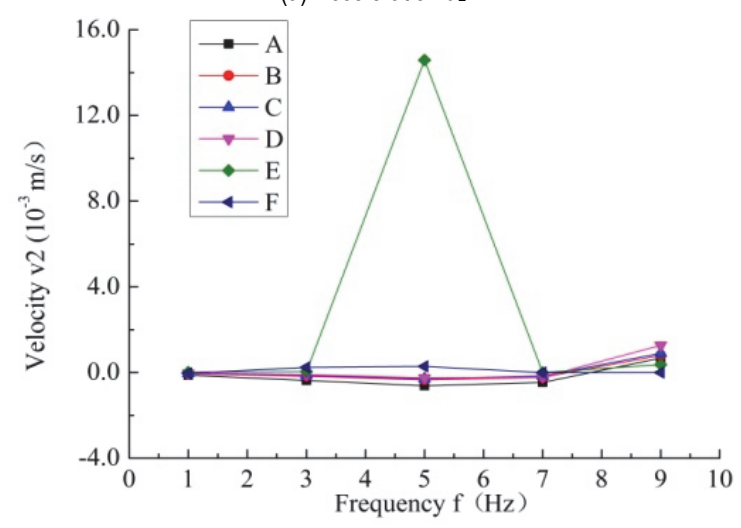

(b) Velocity $v_{2}$

Figure 12 Acceleration and velocity of each monitoring point under traffic load of the same load and different frequency

\subsubsection{Anchorage Cable Axial Force Analysis}

Fig. 13 shows the maximum axial force variation of each anchorage cable after $7 \mathrm{~s}$ of traffic load with the same load and different frequency.

Fig. 13 shows:

(1) The axial force of the four rows of anchorage cables (anchor-1 to anchor-4) of the first and second steps is reduced to the lowest value at a frequency of $5 \mathrm{~Hz}$ after a small change, and then continues to rise.

(2) The axial force of the two rows of anchorage cables (anchor-5, anchor-6) of the third step slightly decreased first. It drops to the lowest value at the frequency of $5 \mathrm{~Hz}$, which rises to the highest value at the frequency of $7 \mathrm{~Hz}$, and then starts to fall again.

It can be considered that the frequency band of $5-7 \mathrm{~Hz}$ is similar to the natural vibration frequency of the simulated slope in this paper. The traffic load and the slope are easy to resonate, which affects the axial force of each anchorage cable. 


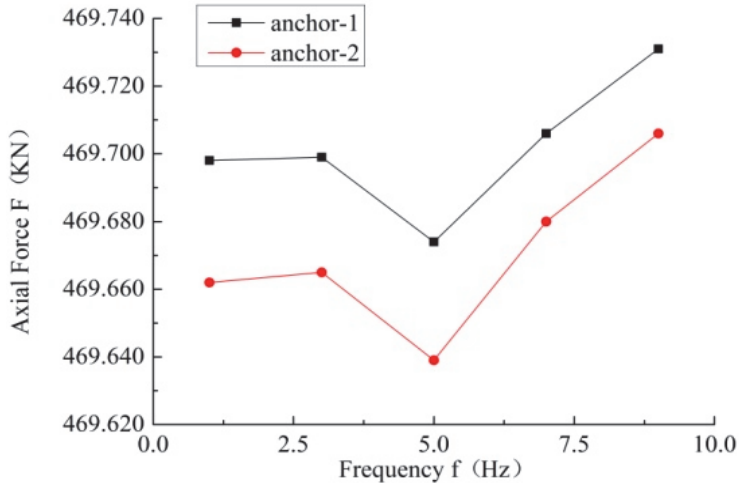

(a) anchor-1, anchor-2

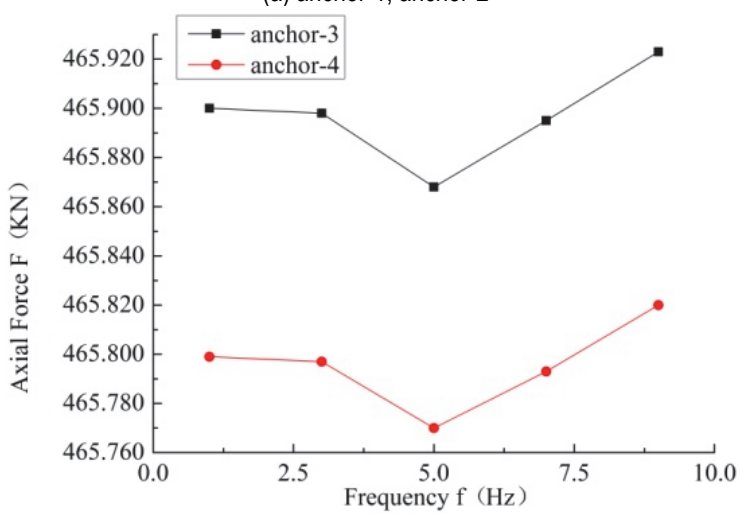

(b) anchor-3, anchor-4

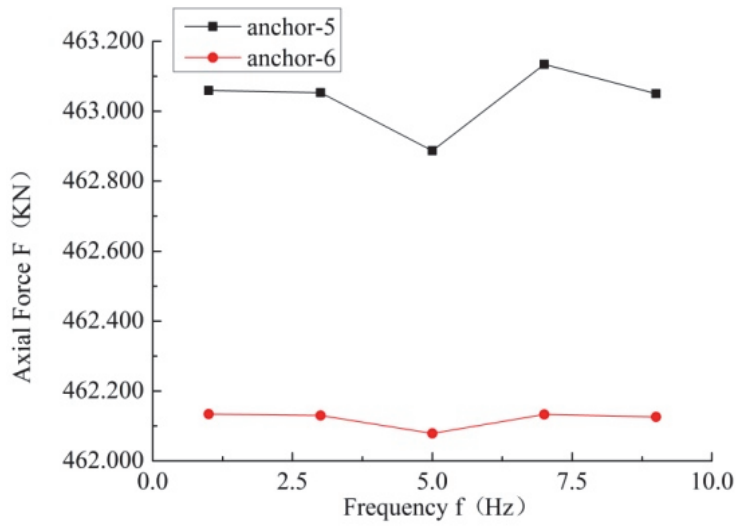

(c) anchor-5, anchor-6

Figure 13 Maximum axial force of each anchor cable under the same frequency and different load

\section{CONCLUSION}

(1) Under the traffic load, the axial force of the anchorage cable starts to rise from the anchor head, reaches a stable value in the free section, and falls to close to zero in the anchorage section.

(2) The axial force of each anchorage cable decreases with the growth of the slope height, and the axial force variation of the anchorage cable decreases with the growth of the distance from the traffic load.

(3) Within the free section of the anchorage cable, there exists a "small platform", where the axial force value decreases slightly and rises, and its position corresponds to the range in which the anchorage cable passes through the joint. In the actual project, whether there is a "small platform" of the measured axial force curve can help to infer the location of loose, broken structural planes or voids in the rock.

(4) The response of rock slope to traffic load. When the vibration frequency of traffic load is constant, the acceleration and velocity of each monitoring point of slope increase with the growth of traffic load. When the amplitude of the traffic load is constant, the acceleration and velocity of each monitoring point of the slope fluctuate with the change of frequency, and there is an unfavorable frequency band range of 5-7 Hz. It can be considered that the frequency band of $5-7 \mathrm{~Hz}$ is similar to the natural frequency of the simulated slope in this paper, and the traffic load and the slope are easy to resonate. Under the long-term effect of traffic load, this resonance phenomenon tends to increase the damage of the slope rock and soil.

(5) The influence of traffic load on acceleration, velocity of each monitoring point and anchorage cable axial force of the slope is not only related to the load size, frequency and vibration duration, but also to the distance from the location of the traffic load, the physical and mechanical parameters of the location, the existence of joints, cracks and other structural planes, and whether or not to take support measures.

(6) The influence of traffic load on acceleration, velocity of each monitoring point and anchorage cable axial force of the slope is not only related to the load size, frequency and vibration duration, but also to the distance from the location of the traffic load, the physical and mechanical parameters of the location, the existence of joints, cracks and other structural planes, and whether or not to take support measures. When the frequency of the traffic load is close to the natural frequency of the slope, the resonance phenomenon is easy to occur, and the damage of the rock and soil of the slope is increased.

\section{Acknowledgments}

This work was kindly supported by Natural Science Foundation of Fujian Province (No.2015J05077), Young and Middle-aged Education Scientific Research Project of Fujian Province (JA15533), China Scholarship Council (CSC, No. 201608350057) and Natural Science Foundation of Fujian Province (No.2016J01206).

\section{REFERENCES}

[1] Liu, Y. Q., Li, H.B., Zhao, J., Li, J. R., \& Zhou, Q. C. (2004). UDEC simulation for dynamic response of a rock slope subject to explosions. International Journal of Rock Mechanics \& Mining Sciences, 41(S1), 599-604. https://doi.org/10.1016/j.jijmms.2004.03.106

[2] Guo, M., Ge, X., \& Wang. H. (2011). Slope stability analysis under seismic load by vector sum analysis method. Journal of Rock Mechanics and Geotechnical Engineering, 3(3), 282-288. https://doi.org/10.3724/SP.J.1235.2011.00282

[3] Pal, S., Kaynia, A. M., Bhasin, R. K., \& Paul, D. K. (2012). Earthquake Stability Analysis of Rock Slopes: a Case Study. Rock Mechanics and Rock Engineering, 45(2), 205-215. https://doi.org/10.1007/s00603-011-0145-6

[4] Bagde, M. N. \& Petroš, V. (2005). Fatigue properties of intact sandstone samples subjected to dynamic uniaxial cyclical loading. International Journal of Rock Mechanics and Mining Sciences, 42(2), 237-250. https://doi.org/10.1016/j.ijrmms.2004.08.008

[5] Enlong, L., Runqiu, H., \& Siming, H. (2012). Effects of Frequency on the Dynamic Properties of Sandstone integrality Samples Subjected to Cyclic Loading under 
Confining Pressure Conditions. Rock Mechanics and Rock Engineering, 45, 89-102. https://doi.org/10.1007/s00603-011-0185-y

[6] Fuenkajorn, K. \& Phueakphum, D. (2010). Effects of cyclic loading on mechanical properties of Maha Sarakham salt. Engineering Geology, 112(1), 43-52. https://doi.org/10.1016/j.enggeo.2010.01.002

[7] Abdelmagied, M. (2019). Analysis of Slope Stability of Canals' Embankments under Traffic Load. Advances in Research, 19(3), 1-12. https://doi.org/10.9734/air/2019/v19i330122

[8] de Farias, M. M., Henrique, A., Júnior, M., \& de Assis, A. P. (2004). Displacement control in tunnels excavated by the NATM: 3-D numerical simulations. Tunnelling and Underground Space Technology, 19(3), 283-293. https://doi.org/10.1016/j.tust.2003.11.006

[9] Ghanbari, E. \& Hamidi, A. (2015). Improvement parameters in dynamic compaction adjacent to the slopes. Journal of Rock Mechanics and Geotechnical Engineering, 27(2), 233236. https://doi.org/10.1016/j.jrmge.2015.02.002

[10] Jafarzadeh, F., Mahdi, M., Hadi, S., \& Jahromi, F. (2015). On the role of topographic amplification in seismic slope instabilities. Journal of Rock Mechanics and Geotechnical Engineering, 7(2), 163-170. https://doi.org/10.1016/j.jrmge.2015.02.009

[11] Zhang, X.-Y. \& Dai, Z.-H. (2009). Stability analysis on jointed rock slope using ABAQUS program. Journal of Guangxi University (Natural Science Edition), 34(4), 444450.

[12] Mei, Y.-B., Zhu, X.-R., \& Lv, F.-R. (2005). Elasto-plastic deformation analysis of pavement and soft subsoil under traffic load. Journal of Zhejiang University (Engineering Science), 39(7), 997-1002.

[13] Chai, J. C. \& Miura, N. (2002). Traffic-load-induced permanent deformation of road on soft subsoil. Journal of Geotechnical Engineering Division, ASCE, 128(11), $907-$ 916. https://doi.org/10.1061/(ASCE)1090-0241(2002)128:11(907)

[14] Li, X.-B. \& Jia, X.-L. (2008). Finite element analysis of the settlement of the soft roadbed under traffic load. Journal of Fuzhou University (Natural Science Edition), 36(4), 604609.

[15] Zhao, Y.-M. (2012). Study on Mechanical Behavior of Epoxy Bonded Bolt System and Bolt Bearing Characteristic in Coal Mine Roadway. China University of Mining and Technology, Xuzhou, Jiangsu, China.

\section{Contact information:}

\section{Run LI}

(Corresponding author)

Engineering College, Fujian Jiangxia University,

Fuzhou 350108, China

E-mail: Ir52tkd25@126.com

\section{Yasi WANG}

Engineering College, Fujian Jiangxia University,

Fuzhou 350108, China 